\title{
Baselines for lifetime of organic solar cells
}

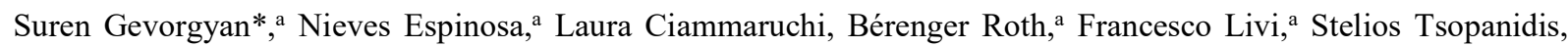
Simon Züfle, Sara Queirós, Alberto Gregori, Gisele Alves dos Reis Benatto, ${ }^{\mathrm{a}}$ Michael Corazza, ${ }^{\mathrm{a}}$ Morten V. Madsen, ${ }^{\mathrm{a}}$ Markus Hösel, ${ }^{\mathrm{a}}$ Michail Beliatis, ${ }^{\mathrm{a}}$ Thue Trofod Larsen-Olsen, ${ }^{\mathrm{a}}$ Francesco Pastorelli, ${ }^{\mathrm{a}}$ António Castro, Alba Mingorance, Veniero Lenzi, Daniel Fluhr, Roland Roesch, Marta Ramos, Achilleas Savva, Harald Hoppe, Luís Silvino Alves Marques, Ignasi Burgués, Efthymios Georgiou, Lucia Serrano, and Frederik C. Krebs ${ }^{\mathrm{a}}$.

a Department of Energy Conversion and Storage, Technical University of Denmark, Frederiksborgvej 399, 4000-Roskilde, Denmark $b \ldots$

$c \ldots$

e-mail:surg@dtu.dk

\section{Highlights}

- Baselines for lifetime of organic solar cells tested under different ageing conditions are presented

- A list of devices with exceptional intrinsic stability is provided

- Lifetime progress diagram with best lifetime is shown

\begin{abstract}
To this date there are no reliable methods for qualifying and guaranteeing the durability of a product made from organic photovoltaics (OPVs) or other similar emerging technologies, such as dye sensitized and perovskites solar cells. The issue however has to be urgently resolved in order to ease the commercialization of such products. The presented work is a part of a larger effort of developing a worldwide database of lifetimes that can help establishing reference baselines of stability performance for OPVs and other emerging PV technologies that can then be utilized for determining and predicting the lifetime of the future products. The study constitutes scanning of literature articles related to stability data of OPVs, reported until mid-2015 and collecting the reported data into a common database. A generic lifetime marker is utilized for
\end{abstract}


rating the stability of various reported devices. The collected data is combined with the earlier developed and reported database, which was based on articles reported until mid-2013. The extended database is then utilized for establishing the baselines of lifetime for OPVs tested under different conditions. The work also provides the recent progress in intrinsic stability of OPVs with different architectures, as well as presents the updated diagram of the reported record lifetimes of OPVs. The presented work is another step forward towards the development of a lifetime prediction tool for emerging PV technologies.

\section{Introduction}

There exists a set of international standards (typically published by IEC and ASTM standards organizations) in the photovoltaic (PV) world that target specific testing and qualification methods for PV based products and enable the possibility for guaranteeing the performance of these products in the end use environment. These standards are typically suitable for silicon based and other inorganic PV technologies. Meanwhile, rapidly developing emerging PV technologies, such as organic photovoltaics (OPV), dye sensitized solar cells (DSSC), perovskite solar cells (PVSK) and others alike still lack standard testing methodologies that would allow reliably predicting their performance in the end use environment. The reason partly comes from the fact that the emerging PVs considerably differ in architecture from their inorganic counterparts [1] and due to their increased sensitivity towards the testing environments [2-5] the common testing standards are not suitable for these technologies [6]. In addition, standards are requirements and recommendations that are created by bringing together the best practices and many experiences of various expert groups in the field, and due to the relatively young age of the emerging technologies and lack of controllable testing procedures there has not been generated sufficient amount of reliable data so far that could lay the basis for development of standards.

These challenges however have received significant attention in the recent years especially in the field of OPVs. In particular, at the sequence of International Summits on Organic solar cell Stability (ISOS) reliable testing of OPVs was thoroughly addressed and in 2011 recommendations were published based on the consensus of a large number of renowned research groups in the field, that outlined recommendations for reliable stability testing of organic solar cell [7]. The guidelines set certain criteria on the test conditions and therefore 
allowed reproducibly recording the ageing of the samples under specific controllable conditions in both indoor and outdoor testing environments. While this very much helped in reducing the spread in the testing procedures among the different groups and improving the reproducibility of the reported device lifetimes [8], the question still remained, how to develop a methodology that would allow predicting and thus guaranteeing the lifetime of a product in end use environment based on accelerated testing. Significant efforts are put today towards resolving this and in particular, recently DTU group has demonstrated an approach based on statistical analyses, where a large set of variety of OPV samples were tested under different ISOS tests and the average lifetime of the samples under each test condition was determined [9,10]. The values were then used to calculate the ratio between the accelerated and real outdoor tests, which could potentially be utilized for predicting device performance. However, despite the relatively large data sets the studies were limited to only a few architectural variations and while they well demonstrated the concept, the established values could not be regarded as sufficiently generic for application beyond the reported studies.

The works however continued and recently a manuscript was published by the same group, where the same statistical approach was utilized for analysing the entire literature related to stability of OPVs [11]. In the study, the authors collected analysed all the articles reported until March 2013 discussing stability studies of OPVs (total of 2500 article). A generic lifetime marker was developed that allowed gauging and intercomparing the stability of the different OPV devices reported in these articles. The lifetime of the samples was categorised depending on device type and architecture and depending on the test conditions, which helped better understanding and elucidating the typical bottlenecks for the device stability. The study additionally helped establishing averages for the lifetimes of OPVs tested under different test conditions. However, due to the limited amount of data for certain test conditions (especially for outdoor data) some averages lacked statistical significance and thus, could not be regarded as reliable baselines for device lifetime. The initiative therefore continued with the purpose of further enriching the lifetime database with both literature reported and experimental data and converting the database into a generic hub of baselines for the lifetime of OPVs and other emerging PV technologies alike and utilizing the data for establishing the prediction tool.

This work, as a complementary to the aforementioned earlier reported study, presents the results of the follow up literature analyses for additional period starting from March-2013 until 
March-2015. The data analysis provides more solidified distributions of the lifetimes and allows drawing conclusions on the baselines for the OPV lifetimes tested under specific conditions. An updated version of the lifetime progress diagram is presented as well.

\section{Methodology}

\subsection{Literature data}

The data collection procedure is explained in detail elsewhere [11]. Briefly the articles were identified using the search engine ScienceDirect and exploring expressions based on different combination of words such as polymer, plastic, organic, solar cells, photovoltaics, stability, ageing and lifetime. The articles that were analysed in an earlier work, also referred to as "older dataset", were removed from the total pile and the remaining articles, referred to as "new dataset", were inserted in an online database for further analyses. The total number of article in the new dataset was 2286, out of which 303 contained actual lifetime data, while the rest only discussed the theory behind the stability issue. The 303 articles presented ageing curve for total of 983 devices, which are called data points. For the comparison, in the earlier article scanning study total of 2500 articles were scanned, which also revealed precisely 303 articles with actual experimental lifetime data. It is worth mentioning that the new dataset contains also articles from conference proceedings dating before 2013 that were not recorded in the older dataset.

\subsection{Lifetime determination}

The online database with the new articles (hosted at http://plasticphotovoltaics.org/ ) was shared among and analysed by different groups from consortia of the COST Actions project (http://www.cost.eu/COST_Actions). The analysis involved scanning each article individually, identifying whether the article contains experimental lifetime data, registering the reported data by filling the database with the reported sample structures, encapsulation, testing conditions and determining the lifetime from the reported ageing curves. The latter was realized by following the steps outlined in the Table 1 and Figure 1 below. A more detailed explanation is provided elsewhere [11]. 

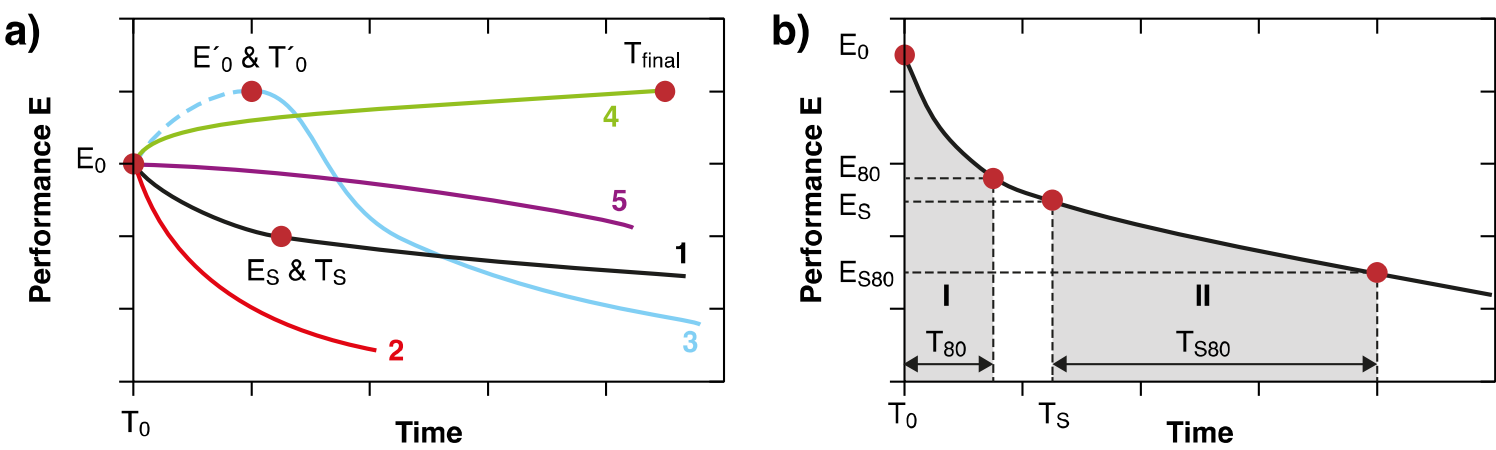

Figure 1. (a) Examples of various typical shapes of ageing curves taken from real data. (b) Example of identifying the best pair describing the stability of the sample. Reprinted with the permission from XXX.

Table 1. The list of steps for determining the lifetime marker. Reprinted with the permission from XXX.

\begin{tabular}{|c|c|}
\hline Parameters & Method \\
\hline $\begin{array}{l}{ }^{*} \text { Determination of starting point } \boldsymbol{E}_{\boldsymbol{0}} \boldsymbol{\&} \boldsymbol{T}_{\boldsymbol{0}} \\
E_{0}-\text { initial performance } \\
T_{0}-\text { initial time }\end{array}$ & $\begin{array}{l}T_{0} \& E_{0} \text { pair is either chosen at the first measurement point or } \\
\text { if the curve has an initial increase followed by a reduction } \\
\text { (such as the curve } 3 \text { in Figure } 1 \text { (a)) then } T_{0} \& E_{0} \text { is set at the } \\
\text { maximum point. }\end{array}$ \\
\hline $\begin{array}{l}\text { Determination of stabilized section } \boldsymbol{E}_{\boldsymbol{S}} \boldsymbol{\&} \boldsymbol{T}_{\boldsymbol{S}} \\
E_{S} \text { - performance at the start of stabilized section } \\
T_{S}-\text { starting time of stabilized section }\end{array}$ & $\begin{array}{l}\text { If after a certain point the ageing curve enters into a more } \\
\text { stable phase (commonly observed during solar cell ageing), } \\
\text { then a second pair of starting values } T_{S} \& E_{S} \text { is identified, } \\
\text { typically chosen at a point from where the ageing rate almost } \\
\text { doesn't change anymore, as shown on curve } 1 \text { in Figure } 1 \text { (a). }\end{array}$ \\
\hline $\begin{array}{l}\text { Determination of } \boldsymbol{T}_{80} \text { and } \boldsymbol{T}_{\boldsymbol{S} 80} \\
T_{80}-\text { time when performance reaches } 80 \% \text { of } E_{0} \\
T_{S 80}-\text { time when performance reaches } 80 \% \text { of } E_{S}\end{array}$ & $\begin{array}{l}T_{80} \text { (or if applicable } T_{S 80} \text { ) is determined by subtracting } T_{0} \text { (or } \\
T_{S} \text { ) from the time when } 80 \% \text { of } E_{0} \text { (or } E_{S} \text { ) is reached. Figure } 1 \\
\text { (b) highlights the areas determined by } T_{80} \text { and } T_{S 80}\end{array}$ \\
\hline Lifetime marker $\left[E_{0} ; T_{80}\right]$ or $\left[E_{S} ; T_{S 80}\right]$ & $\begin{array}{l}\text { The largest area among I and II in Figure } 1 \text { (b) (part of the } \\
\text { curve where the sample produces the largest amount of } \\
\text { energy) will then determine the pair that will describe the } \\
\text { lifetime. The simple geometrical calculations reveal that the } \\
\text { ratio of the areas of the trapezoids I and II are proportional to } \\
\text { the ratio of the areas of the rectangles defined by the products } \\
\text { of } E_{0} \times T_{80} \text { and } E_{S} \times T_{S 80} \text {. Thus the lifetime marker can be } \\
\text { mathematically identified according to these rules: } \\
\text { if } \frac{\left[E_{0} * T_{80}\right]}{\left[E_{S^{*} * T S 8}\right]} \geq 1 \text { then the marker is }\left[E_{0} ; T_{80}\right] \\
\text { if } \frac{\left[E_{0} * T_{80}\right]}{\left[E_{S^{*} * T S 80}\right]}<1 \text { then the marker is }\left[E_{S} ; T_{S 80}\right]\end{array}$ \\
\hline
\end{tabular}


- If $E_{S}$ is less than half of $E_{0}$, in which case the sample is considered to have degraded before stabilization (see curve 2 in Figure $1(\mathrm{a})$ ), then $\left[E_{0} ; T_{80}\right]$ is chosen by default to represent the lifetime.

- If the measurements has been stopped prior to reaching the $80 \%$ threshold then " $T_{\text {final }}-T_{0}$ " or " $T_{\text {final }}-T_{S}$ ", where $T_{\text {final }}$ is the point of last measurement (see curve 4 in Figure 1 (a)) is chosen instead to represent the minimum possible lifetime.

The data is made publicly available at http://plasticphotovoltaics.org/lifetime-predictor.html, where an online interface can be found that allows analysing and reproducing the collected data with application of specific filters. An instruction video is additionally uploaded for navigating though the tool and the database.

\section{Results and discussion}

The data analysed collected from the new dataset was compared with the older dataset. The comparison revealed no significant difference in the data distribution between the two, but rather one complemented the other. The two datasets were therefore combined, which enabled better intercomparison and baselining of the lifetime distributions under different test conditions.

Figure 2 shows the increase in the device stability and quantity of the reported lifetime data in the recent years based on the combination of the two datasets. There is an obvious increase in the values in the recent years with the total number of data points reaching beyond 300, which corresponds to more than 100 articles per year (given that one article contains about 3 data points). This is a clear indication of how important the issue of lifetime has become in the recent years. 




Figure 2. The scatter plot shows the $\mathrm{T}_{80}$ values versus the reporting year for the samples tested under light (green triangles) and in dark (blue circles). The black line shows the number of reported data-points per year until 2014.

\subsection{Baseline for lifetime}

The combination of the two datasets significantly increased the total amount of data points and therefore improved the statistical significance of the lifetime distributions for the samples tested under different test conditions. This enabled the possibility for establishing baselines based on such distributions. In order to do so, the data were categorized according to four groups similar to the earlier work: group 1 and group 2 represented the unencapsulated samples tested under light and in dark respectively and group 3 and group 4 hosted the encapsulated samples tested correspondingly under light and in dark. The tests under light were further distinguished by:

- indoor soaking under light source with spectrum close to AM1.5 and intensity close to 1 sun

- indoor exposure to low UV or low intensity light

- outdoor testing under real sun

Figure 3 shows the lifetime data distribution for each test condition for the stability of the devices with and without encapsulation. Figure 3 (e), (f) and (a) represent the data from group 2, 1 and 4 respectively and Figure (b) - (d) group 3. The data is presented versus the logarithmic scale with base four similar to o-diagram reported earlier [9]. The scale is associated with the common time units shown on the top of the plots, which enables the more intuitive interpretation of the data. Each test category is also associated with the ISOS testing procedures shown in the 
legends. For each data distribution the average and the maximum lifetime region are defined, highlighted respectively with red and green markers. The average represents the most common lifetime values reported for OPVs, while the maximum values show the most outstanding lifetime reports. The corresponding time ranges for average and maximum are listed in the table on the right lower corner of the figure. The group 2 of unencapsulated samples tested in dark contains two average values representing normal and inverted device structures, which are discussed in the next section.

The established baselines can serve as reference points for the performance of any newly produced sample tested under given test conditions:

- If the sample outperforms the average then the sample has an improved stability

- If the performance is in the maximum region or beyond then the sample has an outstanding or record lifetime respectively

As a word of precaution, an attempt to predict the lifetime of the sample in outdoor test conditions based on the ratios of the indoor light soaking and outdoor tests may lead to erroneous results, since one is not the acceleration of the other. For simulation of the outdoor tests a more complicated set of accelerated tests will be required, such as combination of a number of ISOS test procedures. Unfortunately, the database presented in this work does not contain sufficient data for each individual ISOS test procedure at this stage, but with the gradual increase of the database the intercomparison of the data for ISOS will become possible enabling the development of the prediction tool.

Thus, the presented baselines should mainly be regarded as generic reference points for lifetime of organic photovoltaics for given test conditions according to the aforementioned grouping. 

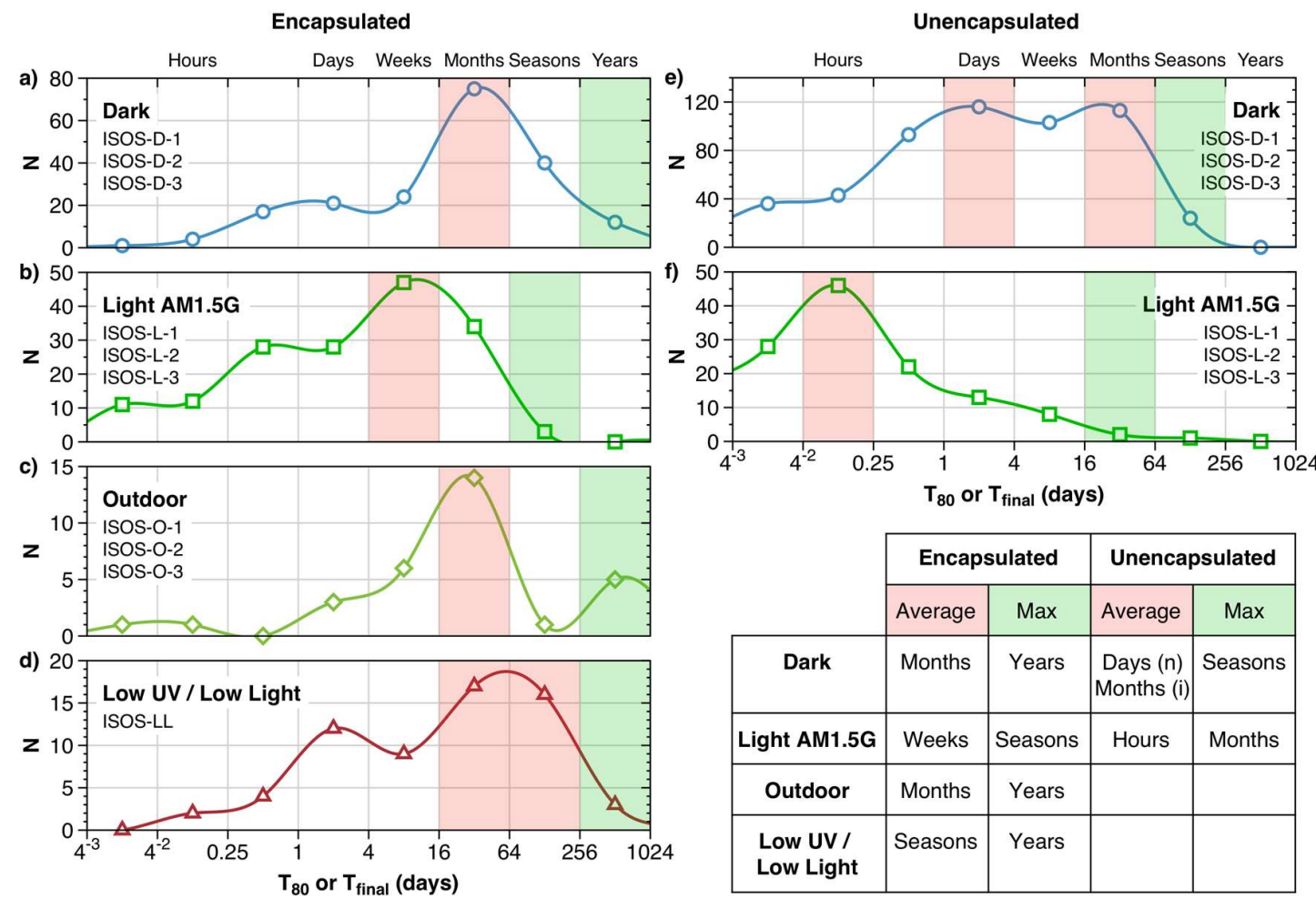

\begin{tabular}{|c|c|c|c|c|}
\cline { 2 - 5 } \multicolumn{1}{c|}{} & \multicolumn{2}{c|}{ Encapsulated } & \multicolumn{2}{c|}{ Unencapsulated } \\
\cline { 2 - 5 } \multicolumn{1}{c|}{} & Average & Max & Average & Max \\
\hline Dark & Months & Years & $\begin{array}{c}\text { Days (n) } \\
\text { Months (i) }\end{array}$ & Seasons \\
\hline Light AM1.5G & Weeks & Seasons & Hours & Months \\
\hline $\begin{array}{c}\text { Outdoor } \\
\text { Low UV / }\end{array}$ & Months & Years & & \\
\hline
\end{tabular}

Figure 3. Baselines of the lifetime of OPVs tested under different ageing conditions for encapsulated (left plots) and unencapsulated (right plots) samples. The plots represent the number of data points against the time in days represented in logarithmic scale with base 4 . The scale is associated with the common time units shown above the plots. The average and maximum lifetime values are highlighted in red and green and are listed in the table on the right lower corner. For unencapsulated samples tested in the dark there are two distinct peaks and thus to average values of days and months representing normal and inverted structures (see section 3.2). The test conditions are associated with but not limited to the ISOS test conditions.

\subsection{Normal vs inverted structures}

In Figure 3 (e) the unencapsulated samples tested in the dark show two distinct peaks. These correspond to device with normal (also known as conventional) and inverted architectures. The former typically employs aluminium back electrode, while the latter has $\mathrm{Ag}$ or $\mathrm{Au}$ based electrode. Figure 4 shows the comparison of the conventional and inverted devices for samples with and without encapsulation. From the figure it is apparent that there is a significant 
difference in the intrinsic stability of the normal and inverted structures, which is less pronounced in the case of the encapsulated samples. It has been established earlier that the normal structures are significantly less resistant towards the moisture due to the high sensitivity of the aluminium [12-14] and therefore show inferior stability when tested in the dark. In the case of encapsulation the sample becomes protected from the humid environment and therefore the reaction of the electrode with moisture is significantly reduced. In the indoor light tests, there is no obvious difference in the stability of the two structures, since the heat produced by the light source creates rather dry environment around the sample diminishing the effect of humidity. As a result the encapsulation of the normal structure devices has a major impact on the stability, while in the case of inverted structures the role of encapsulation does not seem to be significant when the samples are stored in dark as can be seen in Figure 4.
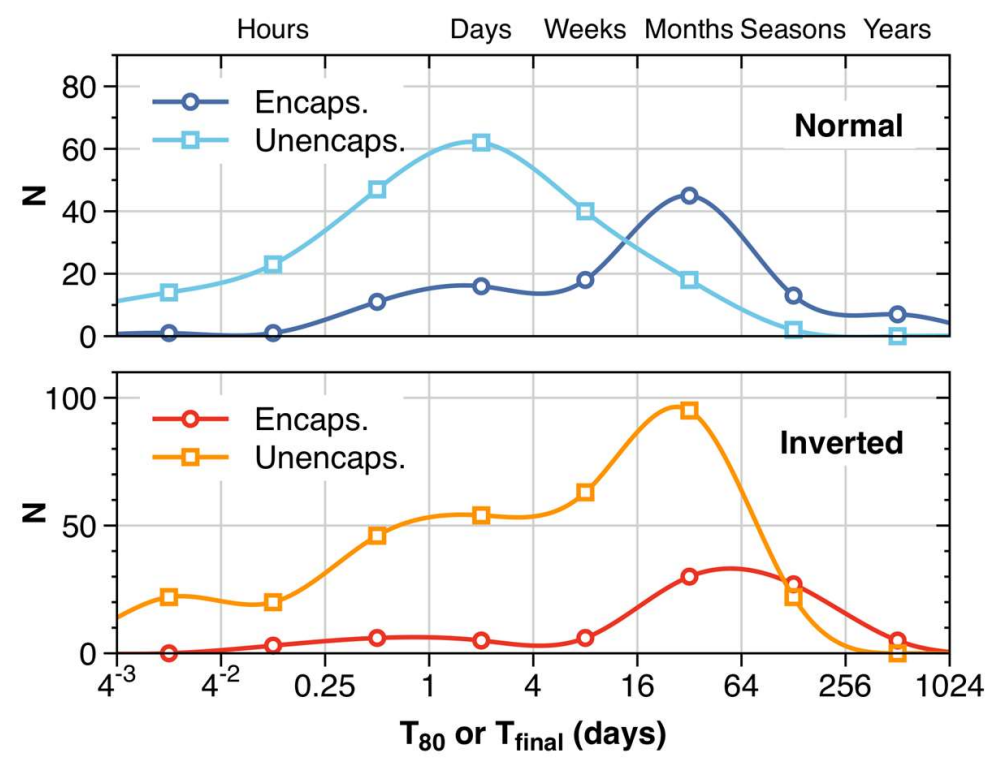

Figure 4. The lifetime distribution of the sample with normal (top) and inverted (bottom) structures tested in the dark. The dark and light curves correspond to encapsulated and unencapsulated samples respectively.

\subsection{Winning Structures}


In the older dataset collected from the earlier article scanning project there was a number of device architectures outlined with reported best intrinsic stabilities (unencapsulated samples). Similarly, in the new dataset a number of reports with samples of outstanding intrinsic stability were registered, which are outlined in the Table 2 below. The table highlights the structures of the reported samples tested under light or in dark and their corresponding lifetime and efficiency values. The most impressive report is the sample tested under light that has showed a lifetime of 96 days [15]. Unfortunately, the details of the top electrode configuration were not reported, but it was stated that it contained a combination of different metals. It is worth mentioning also that one of the samples tested in the dark that showed an outstanding stability of 120 days, was produced in a roll-to-roll compatible process utilizing coating and printing techniques [9]. Nevertheless, despite a number of reports of impressive intrinsic stability, producing samples in a roll-to-roll compatible process with sufficient stability under light test presents a serious challenge that still needs to be addressed [16].

Table 2. The structure and performance parameters of unencapsulated devices tested in dark and under light. The active layer of all the materials is identical and consists of P3HT:PCBM[60].

\begin{tabular}{|c|c|c|c|c|c|}
\hline & \multicolumn{3}{|c|}{ Dark } & \multicolumn{2}{|c|}{ Light } \\
\hline Back Electrode & $\mathbf{A g} / \mathbf{A g}+\mathbf{A l} / \mathbf{A g}$ & Ag grid & Al & $\begin{array}{c}\text { Multilayer } \\
\text { metal electrode }\end{array}$ & Ag \\
\hline $\begin{array}{c}\text { Transport Layer } \\
2\end{array}$ & $\begin{array}{c}\text { *MoOx / } \\
\text { PEDOT:PSS / None }\end{array}$ & PEDOT:PSS & $\mathrm{Cs} 2 \mathrm{CO} 3$ & PEDOT:PSS & MoOx \\
\hline Active Layer & P3НT:РCВМ & P3HT:PCBM & P3HT:PCBM & P3HT:PCBM & P3HT:PCBM \\
\hline $\begin{array}{c}\text { Transport Layer } \\
1\end{array}$ & TiOx / ZnOx / ZnOx & $\begin{array}{l}\text { PEDOT:PSS } \\
\quad+\mathrm{ZnOx}\end{array}$ & $* *$ Other & $\mathrm{ZnOx}$ & $\mathrm{ZnOx}$ \\
\hline Front Electrode & ITO & Ag grid & ITO & ITO & ITO \\
\hline Substrate & Glass & PET & Glass & Glass & Glass \\
\hline Structure & Inverted & Inverted & Normal & Inverted & Inverted \\
\hline PCE (\%) & $3.7 / 3.5 / 2.5$ & 0.93 & 3.6 & 1.9 & 2.85 \\
\hline Lifetime (days) & $198 / 187 / 146$ & 120 & 100 & 96 & 17.5 \\
\hline Reference & {$[17],[18],[19]$} & [9] & {$[20]$} & {$[15]$} & {$[21]$} \\
\hline
\end{tabular}




\subsection{Plot of the record lifetimes}

From the previous report a so called lifetime progress diagram was presented, which highlighted the best reported lifetimes of organic solar cells tested under different test conditions. The diagram has been updated by additions from the new dataset and is presented in Figure 5 . The references of the reports are provided in the table below the image.

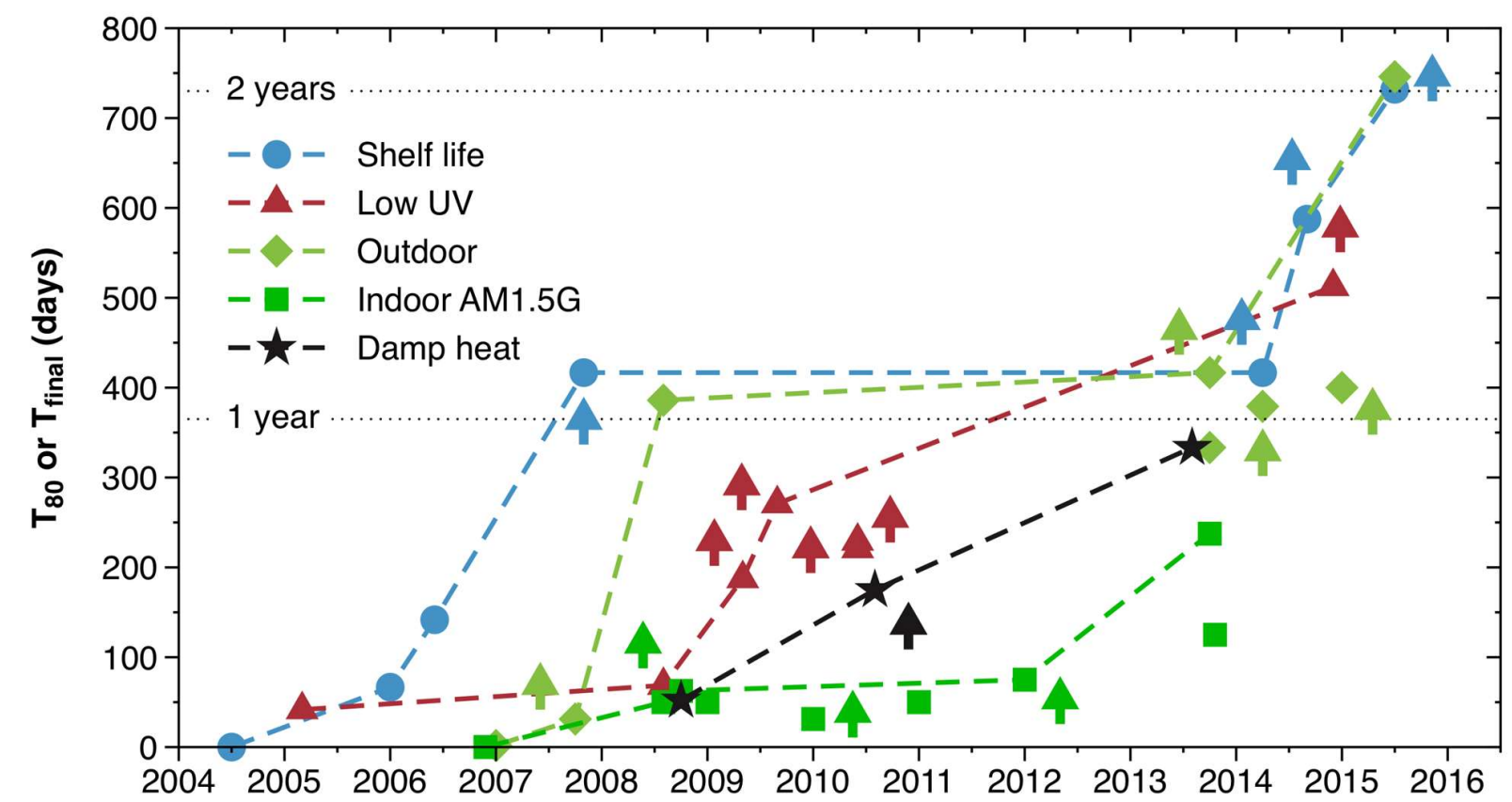

\begin{tabular}{|c|c|c|c|c|c|c|c|c|c|c|c|c|c|c|}
\hline \multicolumn{3}{|c|}{ Indoor AM1.5G } & \multicolumn{3}{|c|}{ Shelf Life } & \multicolumn{3}{|c|}{ Outdoor } & \multicolumn{3}{|c|}{ Low UV } & \multicolumn{3}{|c|}{ Damp Heat } \\
\hline $\begin{array}{l}\text { PCE } \\
(\%)\end{array}$ & $\begin{array}{l}\text { Lifetime } \\
\text { (days) }\end{array}$ & Ref. & $\begin{array}{c}\mathrm{PCE} \\
(\%)\end{array}$ & $\begin{array}{l}\text { Lifetime } \\
\text { (days) }\end{array}$ & Ref. & $\begin{array}{l}\mathrm{PCE} \\
(\%)\end{array}$ & $\begin{array}{c}\text { Lifetime } \\
\text { (days) }\end{array}$ & Ref. & $\begin{array}{l}\text { PCE } \\
(\%)\end{array}$ & $\begin{array}{c}\text { Lifetime } \\
\text { (days) }\end{array}$ & Ref. & $\begin{array}{l}\mathrm{PCE} \\
(\%)\end{array}$ & $\begin{array}{l}\text { Lifetime } \\
\text { (days) }\end{array}$ & Ref. \\
\hline 1.08 & 0.083 & [22] & 0.8 & 0.042 & {$[23]$} & 0.0024 & 2 & [24] & 2.5 & 42 & [25] & $\mathrm{NA}$ & 52 & {$[26]$} \\
\hline NA & 50 & [27] & 0.035 & 67 & {$[28]$} & 4.2 & 31 & [29] & 4.1 & 69 & {$[30]$} & 4.4 & $175^{*}$ & {$[31]$} \\
\hline $\mathrm{NA}$ & 63 & [26] & 0.16 & 142 & {$[32]$} & $\mathrm{NA}$ & 386 & [27] & 2.32 & 188 & [33] & 3 & 333 & {$[34]$} \\
\hline 1.09 & 50 & [35] & 2.8 & 417 & {$[36]$} & 1.43 & 417 & [37] & 5.9 & 271 & {$[38]$} & & & \\
\hline 3.54 & 31 & [39] & 1.27 & 417 & {$[40]$} & 1.43 & 333 & [37] & 2.7 & 229 & [41] & & & \\
\hline NA & 50 & [42] & 6.05 & 587.5 & [43] & NA & 379 & [40] & 6.07 & 221 & [44] & & & \\
\hline 2.1 & 75 & [45] & 1.06 & 732 & {$[46]$} & 1.42 & 400 & [47] & 2.7 & 513 & {$[48]$} & & & \\
\hline 3.42 & 125 & [49] & & & & 1.11 & 746 & [46] & & & & & & \\
\hline 2.59 & 238 & [50] & & & & & & & & & & & & \\
\hline
\end{tabular}

${ }^{*}$ Not compatible with ISOS-D-3 conditions: Tested at $25^{\circ} \mathrm{C}$ air temperature 
Figure 5. The best reported lifetime for each year

\section{Conclusions and future perspective}

This article presented the results of the article analysis published in literature related to the stability of organic solar cells reported in the recent years. The progress in the number of reports per year dealing with the lifetime of OPVs was shown, which asserted the ever increasing interest towards resolving the stability issue of this technology. From the large dataset baselines were determined for the lifetime of OPVs, tested under different conditions, which can serve as a reference point for determining whether a newly reported data has an improved or record lifetime compared to commonly reported values. In addition, a list of devices with outstanding intrinsic stability was highlighted together with the detailed analysis of their structures. The updated version of the diagram of the record stabilities was presented as well. The work constitutes a step forward towards ongoing process of the development of a prediction tool for reliably determining the sample durability. The major challenge is the significant lack of experimental data for each individual ISOS testing condition and in particular for the outdoor tests, which hampers the development of the tool and therefore the work will continue towards generating and collecting more outdoor data.

\section{Acknowledgments}

This work has been supported by COST...

The research leading to these results has received funding from the European Union Seventh Framework Programme (FP7/2007-2013) under grant agreement $n^{\circ} 609788$ (CHEETAH).

\section{References}

[1] J. Jean, P.R. Brown, R.L. Jaffe, T. Buonassisi, V. Bulović, Pathways for solar photovoltaics, Energy Environ. Sci. 8 (2015) 1200-1219. doi:10.1039/C4EE04073B.

[2] M. Jørgensen, K. Norrman, F.C. Krebs, Stability/degradation of polymer solar cells, Sol. Energy Mater. Sol. Cells. 92 (2008) 686-714. doi:10.1016/j.solmat.2008.01.005.

[3] N. Grossiord, J.M. Kroon, R. Andriessen, P.W.M. Blom, Degradation mechanisms in organic photovoltaic devices, Org. Electron. $13 \quad$ (2012) 432-456. doi:10.1016/j.orgel.2011.11.027.

[4] M. Jørgensen, K. Norrman, S.A. Gevorgyan, T. Tromholt, B. Andreasen, F.C. Krebs, 
Stability of polymer solar cells, Adv. Mater. 24 (2012) 580-612. doi:10.1002/adma.201104187.

[5] M. Giannouli, V.M. Drakonakis, A. Savva, P. Eleftheriou, G. Florides, S.A. Choulis, Methods for Improving the Lifetime Performance of Organic Photovoltaics with LowCosting Encapsulation, ChemPhysChem. $16 \quad$ (2015) 1134-1154. doi:10.1002/cphc.201402749.

[6] O. Haillant, Accelerated weathering testing principles to estimate the service life of organic PV modules, Sol. Energy Mater. Sol. Cells. 95 (2011) 1284-1292. doi:10.1016/j.solmat.2010.08.033.

[7] M.O. Reese, S.A. Gevorgyan, M. Jørgensen, E. Bundgaard, S.R. Kurtz, D.S. Ginley, et al., Consensus stability testing protocols for organic photovoltaic materials and devices, Sol. Energy Mater. Sol. Cells. 95 (2011) 1253-1267. doi:10.1016/j.solmat.2011.01.036.

[8] S.A. Gevorgyan, M. Corazza, M. V. Madsen, G. Bardizza, A. Pozza, H. Müllejans, et al., Interlaboratory indoor ageing of roll-to-roll and spin coated organic photovoltaic devices: Testing the ISOS tests, Polym. Degrad. Stab. 109 (2014) 162-170. doi:10.1016/j.polymdegradstab.2014.07.013.

[9] M. Corazza, F.C. Krebs, S.A. Gevorgyan, Predicting, categorizing and intercomparing the lifetime of OPVs for different ageing tests, Sol. Energy Mater. Sol. Cells. 130 (2014) 99106. doi:10.1016/j.solmat.2014.06.031.

[10] M. Corazza, F.C. Krebs, S.A. Gevorgyan, Lifetime of organic photovoltaics: Linking outdoor and indoor tests, Sol. Energy Mater. Sol. Cells. Submitted (2015) Submitted.

[11] S.A. Gevorgyan, M. V. Madsen, B. Roth, M. Corazza, M. Hösel, R.R. Søndergaard, et al., Lifetime of Organic Photovoltaics: Status and Predictions, Adv. Energy Mater. 6 (2016) 1-17. doi:10.1002/aenm.201501208.

[12] M.T. Lloyd, D.C. Olson, P. Lu, E. Fang, D.L. Moore, M.S. White, et al., Impact of contact evolution on the shelf life of organic solar cells, J. Mater. Chem. 19 (2009) 7638. doi:10.1039/b910213b.

[13] M. Wang, F. Xie, J. Du, Q. Tang, S. Zheng, Q. Miao, et al., Degradation mechanism of organic solar cells with aluminum cathode, Sol. Energy Mater. Sol. Cells. 95 (2011) 3303-3310. doi:10.1016/j.solmat.2011.07.020.

[14] V.M. Drakonakis, A. Savva, M. Kokonou, S.A. Choulis, Investigating electrodes degradation in organic photovoltaics through reverse engineering under accelerated humidity lifetime conditions, Sol. Energy Mater. Sol. Cells. 130 (2014) 544-550. doi:10.1016/j.solmat.2014.07.051.

[15] M.T. Lloyd, D.C. Olson, J.J. Berry, N. Kopidakis, M.O. Reese, K.X. Steirer, et al., Enhanced lifetime in unencapsulated organic photovoltaics with air stable electrodes, in: 2010 35th IEEE Photovolt. Spec. Conf., IEEE, 2010: pp. 001060-001063. doi:10.1109/PVSC.2010.5614676.

[16] Michail J. Beliatis, Martin Helgesen, Rafael García-Valverde, Michael Corazza, Bérenger Roth, Jon E. Carlé, Mikkel Jørgensen, Frederik C. Krebs, Suren A. Gevorgyan, Slot die printed V2O5 as hole transport layer for flexible organic opto-electronics on 3D printed scaffolds, Submitted. (2016). 
[17] W. Qiu, R. Müller, E. Voroshazi, B. Conings, R. Carleer, H.-G. Boyen, et al., NafionModified $\mathrm{MoO} x$ as Effective Room-Temperature Hole Injection Layer for Stable, HighPerformance Inverted Organic Solar Cells, ACS Appl. Mater. Interfaces. (2015) 150205111330001. doi:10.1021/am507459t.

[18] E. Voroshazi, I. Cardinaletti, G. Uytterhoeven, A. Hadipour, B.P. Rand, T. Aernouts, Role of electron and hole collecting buffer layers on the stability of inverted polymer: Fullerene photovoltaic devices, in: 2013 IEEE 39th Photovolt. Spec. Conf., IEEE, 2013: pp. 32123215. doi:10.1109/PVSC.2013.6745136.

[19] N. Chaturvedi, S. Kumar Swami, A. Kumar, V. Dutta, Role of ZnO nanostructured layer spray deposited under an electric field in stability of inverted organic solar cells, Sol. Energy Mater. Sol. Cells. 126 (2014) 74-82. doi:10.1016/j.solmat.2014.03.035.

[20] J.-H. Huang, K.-C. Lee, Highly Stable, Solution-Processable Phenothiazine Derivative as Hole Collection Material for Organic Solar Cells, ACS Appl. Mater. Interfaces. 6 (2014) 7680-7685. doi:10.1021/am5009503.

[21] N.K. Elumalai, C. Vijila, R. Jose, K. Zhi Ming, A. Saha, S. Ramakrishna, Simultaneous improvements in power conversion efficiency and operational stability of polymer solar cells by interfacial engineering, Phys. Chem. Chem. Phys. 15 (2013) 19057. doi:10.1039/c3cp53352b.

[22] K. Kawano, R. Pacios, D. Poplavskyy, J. Nelson, D.D.C. Bradley, J.R. Durrant, Degradation of organic solar cells due to air exposure, Sol. Energy Mater. Sol. Cells. 90 (2006) 3520-3530. doi:10.1016/j.solmat.2006.06.041.

[23] S. Heutz, P. Sullivan, B.M. Sanderson, S.M. Schultes, T.S. Jones, Influence of molecular architecture and intermixing on the photovoltaic, morphological and spectroscopic properties of CuPc-C60 heterojunctions, Sol. Energy Mater. Sol. Cells. 83 (2004) 229245. doi:10.1016/j.solmat.2004.02.027.

[24] E.A. Katz, S. Gevorgyan, M.S. Orynbayev, F.C. Krebs, Out-door testing and long-term stability of plastic solar cells, Eur. Phys. J. Appl. Phys. 36 (2006) 307-311. doi:10.1051/epjap:2006159.

[25] X. Yang, J. Loos, S.C. Veenstra, W.J.H. Verhees, M.M. Wienk, J.M. Kroon, et al., Nanoscale morphology of high-performance polymer solar cells, Nano Lett. 5 (2005) 579-583. doi:10.1021/n1048120i.

[26] J.A. Hauch, P. Schilinsky, S.A. Choulis, S. Rajoelson, C.J. Brabec, The impact of water vapor transmission rate on the lifetime of flexible polymer solar cells, Appl. Phys. Lett. 93 (2008) 2008-2010. doi:10.1063/1.2975185.

[27] J.A. Hauch, P. Schilinsky, S.A. Choulis, R. Childers, M. Biele, C.J. Brabec, Flexible organic P3HT:PCBM bulk-heterojunction modules with more than 1 year outdoor lifetime, Sol. Energy Mater. Sol. Cells. 92 (2008) 727-731. doi:10.1016/j.solmat.2008.01.004.

[28] G. Dennler, C. Lungenschmied, H. Neugebauer, N.S. Sariciftci, A. Labouret, Flexible, conjugated polymer-fullerene-based bulk-heterojunction solar cells: Basics, encapsulation, and integration, J. Mater. Res. 20 (2005) 3224-3233. doi:10.1557/jmr.2005.0399.

[29] D.W. Laird, S. Vaidya, S. Li, M. Mathai, B. Woodworth, E. Sheina, et al., Advances in 
Plexcore active layer technology systems for organic photovoltaics: roof-top and accelerated lifetime analysis of high performance organic photovoltaic cells, in: SPIE 6656, Org. Photovoltaics VIII, 2007: p. 66560X-66560X-8. doi:10.1117/12.734711.

[30] R. Franke, B. Maennig, A. Petrich, M. Pfeiffer, Long-term stability of tandem solar cells containing small organic molecules, Sol. Energy Mater. Sol. Cells. 92 (2008) 732-735. doi:10.1016/j.solmat.2007.12.001.

[31] J.H. Tsai, Y.C. Lai, T. Higashihara, C.J. Lin, M. Ueda, W.C. Chen, Enhancement of P3HT/PCBM photovoltaic efficiency using the surfactant of triblock copolymer containing poly(3-hexylthiophene) and poly(4- vinyltriphenylamine) segments, Macromolecules. 43 (2010) 6085-6091. doi:10.1021/ma1011182.

[32] C. Lungenschmied, G. Dennler, G. Czeremuzskin, M. Latrèche, H. Neugebauer, N.S. Sariciftci, Flexible encapsulation for organic solar cells, in: SPIE 6197, Photonics Sol. Energy Syst., 2006: pp. 619712-619712-8. doi:10.1117/12.662829.

[33] B. Zimmermann, U. Würfel, M. Niggemann, Longterm stability of efficient inverted P3HT:PCBM solar cells, Sol. Energy Mater. Sol. Cells. 93 (2009) 491-496. doi:10.1016/j.solmat.2008.12.022.

[34] F. Yan, J. Noble, J. Peltola, S. Wicks, S. Balasubramanian, Semitransparent OPV modules pass environmental chamber test requirements, Sol. Energy Mater. Sol. Cells. 114 (2012) 214-218. doi:10.1016/j.solmat.2012.09.031.

[35] R. Tipnis, J. Bernkopf, S. Jia, J. Krieg, S. Li, M. Storch, et al., Large-area organic photovoltaic module-Fabrication and performance, Sol. Energy Mater. Sol. Cells. 93 (2009) 442-446. doi:10.1016/j.solmat.2008.11.018.

[36] W.J. Potscavage, S. Yoo, B. Domercq, J. Kim, J. Holt, B. Kippelen, Integrated organic photovoltaic modules, in: SPIE 6656, Org. Photovoltaics VIII, 2007: p. 66560R-66560R10. doi:10.1117/12.735320.

[37] S.A. Gevorgyan, M. V. Madsen, H.F. Dam, M. Jørgensen, C.J. Fell, K.F. Anderson, et al., Interlaboratory outdoor stability studies of flexible roll-to-roll coated organic photovoltaic modules: Stability over 10,000 h, Sol. Energy Mater. Sol. Cells. 116 (2013) 187-196. doi:10.1016/j.solmat.2013.04.024.

[38] G. Schwartz, B. Maennig, C. Uhrich, W. Gnehr, S. Sonntag, O. Erfurth, et al., Efficient and long-term stable organic vacuum deposited tandem solar cells, in: SPIE 7416, Org. Photovoltaics X, 2009: p. 74160K-74160K-11. doi:10.1117/12.828955.

[39] D. Gao, M.G. Helander, Z. Bin Wang, D.P. Puzzo, M.T. Greiner, Z.H. Lu, C60:LiF blocking layer for environmentally stable bulk heterojunction solar cells, Adv. Mater. 22 (2010) 5404-5408. doi:10.1002/adma.201002738.

[40] D. Angmo, P.M. Sommeling, R. Gupta, M. Hösel, S.A. Gevorgyan, J.M. Kroon, et al., Outdoor operational stability of indium-free flexible polymer solar modules over 1 year studied in India, Holland, and Denmark, Adv. Eng. Mater. (2014). doi:10.1002/adem.201400002.

[41] M. Hermenau, K. Leo, M. Riede, Comparison of different conditions for accelerated ageing of small molecule organic solar cells, in: SPIE 7722, Org. Photonics IV, 2010: p. 77220K-77220K-10. doi:10.1117/12.853834. 
[42] S. Cros, R. De Bettignies, S. Berson, S. Bailly, P. Maisse, N. Lemaitre, et al., Definition of encapsulation barrier requirements: A method applied to organic solar cells, Sol. Energy Mater. Sol. Cells. 95 (2011) 65-69. doi:10.1016/j.solmat.2011.01.035.

[43] J. Kong, S. Song, M. Yoo, G.Y. Lee, O. Kwon, J.K. Park, et al., Long-term stable polymer solar cells with significantly reduced burn-in loss, Nat. Commun. 5 (2014) 5688. doi:10.1038/ncomms6688.

[44] C.L. Uhrich, G. Schwartz, B. Maennig, W.M. Gnehr, S. Sonntag, O. Erfurth, et al., Efficient and long-term stable organic vacuum deposited tandem solar cells, in: SPIE 7722, Org. Photonics IV, 2010: p. 77220G-77220G-8. doi:10.1117/12.855088.

[45] D.M. Tanenbaum, M. Hermenau, E. Voroshazi, M.T. Lloyd, Y. Galagan, B. Zimmermann, et al., The ISOS-3 inter-laboratory collaboration focused on the stability of a variety of organic photovoltaic devices, RSC Adv. 2 (2012) 882. doi:10.1039/c1ra00686j.

[46] D. Angmo, F.C. Krebs, Stable over 2 years in outdoor and storage conditions: ITO-free, fully roll-to-roll fabricated polymer solar cell modules, (2015) accepted for publication. doi:10.1002/ente.201500086.

[47] B. Roth, G.A. dos Reis Benatto, M. Corazza, R.R. Søndergaard, S.A. Gevorgyan, M. Jørgensen, et al., The Critical Choice of PEDOT:PSS Additives for Long Term Stability of Roll-to-Roll Processed OPVs, Adv. Energy Mater. 5 (2015) 1401912. doi:10.1002/aenm.201401912.

[48] S.B. Sapkota, A. Spies, B. Zimmermann, I. Dürr, U. Würfel, Promising long-term stability of encapsulated ITO-free bulk-heterojunction organic solar cells under different aging conditions, Sol. Energy Mater. Sol. Cells. 130 (2014) 144-150. doi:10.1016/j.solmat.2014.07.004.

[49] R. Roesch, K.R. Eberhardt, S. Engmann, G. Gobsch, H. Hoppe, Polymer solar cells with enhanced lifetime by improved electrode stability and sealing, Sol. Energy Mater. Sol. Cells. 117 (2013) 59-66. doi:10.1016/j.solmat.2013.05.013.

[50] A. Karpinski, S. Berson, H. Terrisse, M. Mancini-Le Granvalet, S. Guillerez, L. Brohan, et al., Anatase colloidal solutions suitable for inkjet printing: Enhancing lifetime of hybrid organic solar cells, Sol. Energy Mater. Sol. Cells. 116 (2013) 27-33. doi:10.1016/j.solmat.2013.04.006. 